\title{
ALTERATION OF PHARMACOKINETIC PARAMETERS OF PROTON PUMP INHIBITORS USING TRANSDERMAL DRUG DELIVERY SYSTEM
}

\author{
M. R. SHIVALINGAM, ARUL BALASUBRAMANIAN*, KOTHAI RAMALINGAM
}

Department of Pharmacy Practice, Vinayaka Mission's College of Pharmacy, Vinayaka Mission's Research Foundation (Deemed to be University), Salem 636008, Tamilnadu, India

Email: arul1971@yahoo.com

Received: 02 Jul 2021, Revised and Accepted: 28 Jul 2021

ABSTRACT

Objective: The present study was aimed to find out the effect of transdermal patches of proton pump inhibitors pantoprazole and esomeprazole on the alteration of pharmacokinetic parameters of these drugs.

Methods: The transdermal patches were formulated by the solvent evaporation technique using polymers $\mathrm{HPMC}_{5}$ with PVP K 30 and HPMC $\mathrm{E}_{5}$ with Eudragit L100 in different ratios. The best formulation from each of the drug pantoprazole and esomeprazole was selected and administered to rabbits and the plasma drug concentration was compared with the marketed formulation. The pharmacokinetic parameters such as maximum plasma concentration $\left(\mathrm{C}_{\max }\right)$, time to reach $\mathrm{C}_{\max }\left(\mathrm{t}_{\max }\right)$, area under the curve (AUC), area under first moment curve (AUMC), elimination rate constant $\left(\lambda_{z}\right)$, biological half-life $\left(t_{1 / 2}\right)$, and mean residence time (MRT) were determined.

Results: The plasma drug concentration vs time curve shows the extended-release of the drugs pantoprazole and esomeprazole when compared with the marketed formulation. The results show that there is no change in the peak plasma concentration, but a significant difference was observed in all the pharmacokinetic parameters. The AUC showed 6 fold increase for pantoprazole from 8.91 to $55.20 \mu \mathrm{g} * \mathrm{~h} / \mathrm{ml}$ and 3.5 fold increase for the drug esomeprazole from 7.86 to $28.53 \mu \mathrm{g} * \mathrm{~h} / \mathrm{ml}$, and the mean residence time also showed 2 fold increase for the transdermal patches when compared with the marketed formulations.

Conclusion: The increase in $t_{\max }$ AUC, and MRT values of the formulated transdermal patches with the values of the marketed formulation of both the drugs, revealed that the transdermal patches can be used to deliver the drug for an extended period and also can alter the pharmacokinetics of pantoprazole and esomeprazole.

Keywords: Transdermal patches, Pantoprazole sodium, Esomeprazole magnesium, Pharmacokinetics

(C) 2021 The Authors. Published by Innovare Academic Sciences Pvt Ltd. This is an open access article under the CC BY license (https://creativecommons.org/licenses/by/4.0/) DOI: https://dx.doi.org/10.22159/ijap.2021v13i5.42617. Journal homepage: https://innovareacademics.in/journals/index.php/ijap

The transdermal drug delivery system (TDDS) is a widely accepted mode of drug delivery, and transdermal patches are designed for the treatment of different diseases [1]. Transdermal deliveries lead to more compliance with the patient and avoidance of the first-pass metabolism via injectable and oral routes. They can even avoid gastrointestinal issues and low absorption associated with medicines [2]. The objective of the transdermal system of the delivery of medicines is to maximize skin flow to the systemic circulation while simultaneously reducing skin retention and metabolism [3-5]. These therapeutic benefits reflect the higher marketing potential of TDDS [6]. The role of permeating or penetrating enhancers in TDDS is therefore, essential as they reduce the barrier resistance to stratum corneum reversibly without damaging viable cells [7]. The FDA in 1981, approves the first transdermal patch developed by Alza corp, California and because of its constant success, 35 TDDS patches for various conditions are currently on the market [8].

A peptic ulcer forms a sore when the lining of the digestive system wears off digestive juices and may occur in the stomach lining, duodenum, or lower part of the esophagus. That is why peptic ulcer is considered both morbid and mortal as a complicated disease and a major health hazard [9].

Overall, up to $10 \%$ of adults are estimated to be affected at least once in life by peptic ulcers. Patients who test negative for $H$. pyloriare prescribed conventional proton pump inhibitor (PPIs) tablets. There is a lack of bioavailability with $H$. pylori infection, showing a lower drug availability at the site of action in peptic ulcers (GERD), which does not, in turn, provide the therapeutically required efficiency. Treatment usually takes 1-2 mo, but treatment may continue longer if the ulcer is severe $[4,10,11]$

Pantoprazole is a substituted benzimidazole sulphoxide for the treatment of acid-related gastrointestinal diseases such as reflux esophagitis, duodenal and gastric ulcers. Pantoprazole, administered as a $40 \mathrm{mg}$ enteric-coated tablet, is quantitatively absorbed. Its absolute bioavailability is $77 \%$ and does not change upon multiple dosing [12]. Pantoprazole shows linear pharmacokinetics after both i. v. and oral administration. Pantoprazole is extensively metabolized in the liver, and to overcome these problems the current study was aimed to formulate a transdermal drug delivery system for it.

Esomeprazole magnesium trihydrate has been approved by the FDA for the treatment of gastroesophageal reflux disease, short-term treatment, and the maintenance of erosive esophagitis, as standard PPIs. Esoméprazole is an omeprazole S-isomer that has been developed as an optical isomer as the first PPI [13]. The pharmacokinetic profile of the medication has improved, leading to greater systemic exposure and lower interpersonal variability than omeprazole, and a better suppression of the production of gastric acid in comparison with other PPIs. It is $89 \%$ bioavailable, and the elimination half-life is 1.5h [14]. With the corresponding reduction in $\mathrm{pH}$ of the media, the stability of the esomeprazole magnesium trihydrate decreases.

The acidic contents of the stomach would therefore lead to significant degradation of the medicament and lower bioavailability with esomeprazole magnesium trihydrate exposure [13].

PPIs in the form of parenteral are used to get maximum bioavailability by avoiding first-pass hepatic metabolism through an invasive route with certain limitations. In this study, an attempt was made to formulate a transdermal therapeutic system for pantoprazole and esomeprazole in the form of transdermal patches to release the drug through the skin at a controlled rate into the systemic circulation and to maintain drug concentration within the therapeutic window, thereby reducing the adverse effects of the drug.

Pantoprazole and Esomeprazole were obtained as a gift sample from Dr. Reddy's Laboratories Ltd, Hyderabad. PVA and Sodium 
hydroxide are purchased from Thomas Baker (Chemicals) Pvt Ltd, Mumbai. HPLC-grade Potassium dihydrogen phosphate $\left(\mathrm{KH}_{2} \mathrm{PO}_{4}\right)$, acetonitrile (purity not less than 99.80\%), methanol and triple distilled water, and o-phosphoric acid were used as received from Merck India Ltd. (Mumbai, India). HPMC $\mathrm{E}_{5}$ was purchased from Loba Chemie Pvt Ltd, Mumbai. PVP, Methanol, Chloroform, Dibutyl phthalate, DMSO are purchased from Research-Lab Fine Chem Industries, Mumbai. Eudragit L100 was purchased from Rohm Pharma, Germany. All the other reagents are all of the analytical grades obtained from Shaimil Laboratories Ltd., Baroda, India. (99.69-99.99\% quality).

Every six batches of transdermal films containing Pantoprazole sodium and Esomeprazole magnesium were cast on a petri dish by a solvent evaporation method using different polymers (HPMC E5:PVP K30 and HPMC E5:Eudragit L 100) [15]. The drug to polymer ratio was fixed as $1: 1$ and the polymer to polymer ratio was fixed as 1:1, 1:2, and 2:1 [16]. Three different concentrations of HPMC E5 were used in all six formulations and another two polymers PVP K 30 and Eudragit L100 were used in every three formulations at varying concentrations (table 1). N-dibutyl phthalate and propylene glycol were used as a plasticizer. 1\% DMSO was used as a permeation enhancer in all the formulations [17].

The polymers were accurately weighed and dissolved in $10 \mathrm{~mL}$ of ethanol and in the case of Eudragit L 100, the chloroform: methanol (1:1) solution was also used and kept aside to form a clear solution. Drug pantoprazole sodium was dissolved in the above solution and mixed until a clear solution was obtained. Then the plasticizer and the permeation enhancers were added to the formulation step by step and mixed uniformly. The resulted uniform solution was cast on the petri dish, which was lubricated with glycerin and dried at room temperature for $2 \mathrm{At}$ An inverted funnel was placed over the petri dish to prevent fast evaporation of the solvent. After 2 the dried patches were taken out and stored in a desiccator for further studies [18].

Table 1: Formulation details of pantoprazole sodium and esomeprazole magnesium transdermal patches

\begin{tabular}{|c|c|c|c|c|c|c|c|c|c|c|c|c|}
\hline \multirow[t]{2}{*}{ Ingredients } & \multicolumn{12}{|c|}{ Formulations } \\
\hline & F1 & F2 & F3 & F4 & F5 & F6 & F7 & F8 & F9 & F10 & F11 & F12 \\
\hline Pantoprazole Sodium (mg) & 635 & 635 & 635 & 635 & 635 & 635 & - & - & - & - & - & - \\
\hline Esomeprazole Magnesium & - & - & - & - & - & - & 635 & 635 & 635 & 635 & 635 & 635 \\
\hline HPMC $\left(E_{5}\right)(\mathrm{mg})$ & 300 & 200 & 400 & 300 & 200 & 400 & 300 & 200 & 400 & 300 & 200 & 400 \\
\hline PVP K 30 (mg) & 300 & 400 & 200 & - & - & - & 300 & 400 & 200 & - & - & - \\
\hline Eudragit L 100 (mg) & - & - & - & 300 & 400 & 200 & - & - & - & 300 & 400 & 200 \\
\hline Ethanol $(\mathrm{ml})$ & 10 & 10 & 10 & 10 & 10 & 10 & 10 & 10 & 10 & 10 & 10 & 10 \\
\hline Chloroform: Methanol (1:1) (ml) & - & - & - & 6 & 6 & 6 & - & - & - & 6 & 6 & 6 \\
\hline n-Dibutyl Phthalate (ml) & 8.5 & 8.5 & 8.5 & 8.5 & 8.5 & 8.5 & 8.5 & 8.5 & 8.5 & 8.5 & 8.5 & 8.5 \\
\hline Propylene glycol (ml) & 0.5 & 0.5 & 0.5 & 0.5 & 0.5 & 0.5 & 0.5 & 0.5 & 0.5 & 0.5 & 0.5 & 0.5 \\
\hline DMSO (ml) & 0.1 & 0.1 & 0.1 & 0.1 & 0.1 & 0.1 & 0.1 & 0.1 & 0.1 & 0.1 & 0.1 & 0.1 \\
\hline
\end{tabular}

(All quantities are in $\mathrm{mg} / \mathrm{ml}$ )

The prepared transdermal drug delivery system of Pantoprazole sodium and Esomeprazole magnesium using different polymers HPMC E5, PVP K30, and Eudragit L100 were evaluated and had shown good promising results for all the evaluated parameters. From the in vitro studies, it was confirmed that the formulations F1 and F7 formulated with HPMC E5: PVP K30 in the ratio of 1:1 released the drugs pantoprazole $98.99 \%$ and Esomeprazole 95.93 $\%$ respectively at $24 \mathrm{~h} \mathrm{[16].} \mathrm{So,} \mathrm{these} \mathrm{two} \mathrm{formulations} \mathrm{were} \mathrm{selected}$ for the pharmacokinetic studies on rabbits.

Female New Zealand white rabbits of either sex and approximately the same age, weighing about 1.5 to $1.75 \mathrm{~kg}$, procured from Sri Venkateswara Enterprises, Bengaluru (Reg No. 237/99), were used for the study [19]. They were housed in separate metallic cages and fed with a standard chow diet and water ad libitum. The animals were exposed to an alternate cycle of $12 \mathrm{~h}$ of darkness and light each. Before each test, the animals fasted for at least $12 \mathrm{~h}$. The experimental protocols were subjected to the scrutinization of the Institutional Animal Ethics Committee and were cleared by the same (Approval No. P. COL/25/2021/IAEC/VMCP). The animals were divided into 4 groups, each consisting of three. The first group was administered with the transdermal batches of pantoprazole (F1) and the second group was treated with the transdermal patches of esomeprazole (F7). The third and fourth groups were administered with marketed pantoprazole $40 \mathrm{mg}$ and esomeprazole $40 \mathrm{mg}$ tablets, respectively, along with $100 \mathrm{ml}$ of water.

Before the patches were applied, the abdominal site of the rabbit was shaved and cleaned with saline. The skin of the rabbits was checked carefully in case of any skin breakage. The blood samples were collected into heparinized vacuum tubes at $0.25,0.5,1,2,3,4$, $6,8,10,12,1620$, and $24 \mathrm{~h}$ following the Pantoprazole or Esomeprazole administration. After collection, the blood samples were centrifuged at $1000 \mathrm{rpm}$ for $10 \mathrm{~min}$ at room temperature (25 ${ }^{\circ} \mathrm{C}$ ); followed by direct transfer into microcentrifuge tubes and stored at $-70^{\circ} \mathrm{C}$ until analysis. The amount of food and water intake for each animal was standardized during the sampling day.
The stock solution was prepared by weighing pantoprazole $(40 \mathrm{mg})$ and esomeprazole $(40 \mathrm{mg}$ ) separately in a $100-\mathrm{ml}$ volumetric flask, dissolved in methanol, and diluted to volume with the same solvent. Of these solutions, $1.0 \mathrm{ml}$ was further diluted to $100 \mathrm{ml}$ with mobile phase to obtain $\left(4,000 \mathrm{ng} \mathrm{ml}^{-1}\right)$ and esomeprazole $\left(4,000 \mathrm{ng} \mathrm{ml}^{-1}\right)$. The standard working solutions of pantoprazole and esomeprazole were produced by diluting the stock solutions with blank rabbit plasma (1:1).

Pantoprazole and esomeprazole were used as an internal standard for each other. Esomeprazole was used as IS for the determination of pantoprazole and pantoprazole was used as IS for the determination of esomeprazole. The internal standard solution was prepared by weighing pantoprazole $(4 \mathrm{mg})$ and esomeprazole $(4 \mathrm{mg})$ in a $100-\mathrm{ml}$ volumetric flask, dissolved in methanol and diluted to volume with the same solvent. Of these solutions, $1.0 \mathrm{ml}$ was further diluted to $100 \mathrm{ml}$ with mobile phase to obtain a concentration of pantoprazole (400 ng ml-1) and esomeprazole (400 ng ml-1). Solutions were freshly prepared before use.

The Phosphate Buffer Solution was prepared by using $\mathrm{KH}_{2} \mathrm{PO}_{4}$ (6.8 g), previously dried for $2 \mathrm{~h}$ at $120 \pm 5^{\circ} \mathrm{C}$, was dissolved in triple distilled water, diluted to $1,000 \mathrm{ml}$ with the same solvent, and adjusted to $\mathrm{pH} 4.70 \pm 0.1$ with $85 \%$ orthophosphoric acid.

The calibration curve was prepared by an accurately measured standard working solution of Pantoprazole and Esomeprazole (1.0, 2.0, 4.0,6.0, 8.0, $10.0 \mathrm{ml}$ ) were transferred in a series of $10 \mathrm{ml}$ of volumetric flask and diluted to the mark with the mobile phase. Calibration curves were plotted over the concentration range of pantoprazole and esomeprazole $(400,800,1,600,2,400,3,200$, $4,000 \mathrm{ng} \mathrm{ml}-1)$. Twenty microliters of each solution were injected under the operating chromatographic conditions described above. Each solution was injected five times. The least-squares method was used for the calculation of slope, intercept, and correlation coefficient (r). For all the compounds, the correlation between the peak area and substance concentration was described by linear regression equations with high values of correlation coefficient $(r)$. 
The plasma samples were prepared by taking $1 \mathrm{ml}$ of the plasma samples transferred to a $15 \mathrm{ml}$ glass tube and 4-ml of tert-butyl methyl ether was added to the pantoprazole samples and $5 \mathrm{ml}$ of dichloromethane was added to the esomeprazole samples. The mixtures were vortexed for 3 min then centrifuged at 3,000 rpm for $15 \mathrm{~min}$. The $4 \mathrm{ml}$ of the organic phase was transferred to another tube and evaporated at $37{ }^{\circ} \mathrm{C}$ under a stream of nitrogen. The residue was reconstituted with $100 \mu \mathrm{l}$ mobile phase [potassium dihydrogen phosphate buffer-acetonitrile, $72: 28(\mathrm{v} / \mathrm{v})]$. and injected into the chromatographic system [20-22].

An HPLC instrument of LC-10AT VP series (Shimadzu Corporation, Switzerland) consisting of a UV-Visible detector, manual injector with $20 \mu \mathrm{L}$ loop, and Hypersil BDS C18 column $(250 \mathrm{~mm} \times 4.6 \mathrm{~mm}$ i.d., $5 \mu \mathrm{m}$ particle size) was used. A Beckman Instruments (Fullerton, $\mathrm{CA}$, USA) U50 $\mathrm{pH}$ meter was used for $\mathrm{pH}$ control; the instrument has previously been calibrated against standard buffer solutions of $\mathrm{pH}$ $1.68,3.56,4.01$, and 6.86 .

Chromatography was performed on a Hypersil C18 (2) reversephase column $(250 \mathrm{~mm} \times 4.6 \mathrm{~mm}$ i.d., $5 \mu \mathrm{m})$ base deactivated silyl bonded amorphous silica. The mobile phase was potassium dihydrogen phosphate buffer-acetonitrile, 72:28 (v/v). Flow-rate was $1.0 \mathrm{ml}$ min- 1 . The column was kept at $25.0 \pm 0.1{ }^{\circ} \mathrm{C}$ during the analysis; the detection wavelength was $210 \mathrm{~nm}$ and the injection volume was $20 \mu \mathrm{l}$.

The method exhibited linearity of response over a range of 400$4000 \mathrm{ng} / \mathrm{ml}$ for both pantoprazole and esomeprazole. The limit of detection and limit of quantification was found to be 147.51 and $399.63 \mathrm{ng} / \mathrm{ml}$ for pantoprazole and 131.27 and $397.79 \mathrm{ng} / \mathrm{ml}$ for esomeprazole. The within-batch precision ranged from $0.74-1.73 \%$ for pantoprazole and 0.43-0.65 \% for esomeprazole. The accuracy ranged from 99.91-100.20 for pantoprazole and 98.96-99.85 \% for esomeprazole. The stability of the samples under frozen conditions, at room temperature, and during the freeze-thaw cycle was also determined. The accuracy and precision for calibration curve standards and quality samples in all bioanalytical methods met the acceptance criteria as per FDA guidelines.

Pharmacokinetic evaluation non-compartmental modeling was used to estimate the pantoprazole and esomeprazole pharmacokinetic parameters after single-dose administration. The plasma concentration vs time data was evaluated by using PKSolver. Pharmacokinetic parameters such as maximum drug concentration $\left(\mathrm{C}_{\max }\right)$ in plasma, the time that $\mathrm{C}_{\max }$ occurred $\left(\mathrm{t}_{\max }\right)$, area under the plasma concentration-time curve from 0 to $24 \mathrm{~h}\left(\mathrm{AUC}_{0-\mathrm{t}}\right)$ and 0 to infinity $\left(\mathrm{AUC}_{0-\infty}\right)$, elimination rate constant $\left(\lambda_{z}\right)$, biological half-life $\left(\mathrm{t}_{1 / 2}\right)$, Apparent volume of distribution during terminal phase after non-intravenous administration $(\mathrm{Vz} / \mathrm{F})$, Apparent total clearance of the drug from plasma after oral administration $(\mathrm{Cl} / \mathrm{F})$ and mean residence time (MRT) were determined.

The area under the plasma concentration versus time curve from 0 to $24 \mathrm{~h}$ ( $\mathrm{AUC}_{0-\mathrm{t}}$ ) was assessed using the linear trapezoidal methodology and was extrapolated to infinity $\left(\mathrm{AUC}_{0-\infty}\right)$. The maximum plasma concentration $\left(\mathrm{C}_{\max }\right)$ and time to reach $\mathrm{C}_{\max }\left(\mathrm{t}_{\max }\right)$ for pantoprazole and esomeprazole were directly obtained from the individual observed data. The terminal phase elimination rate $(\lambda z)$ was estimated using a log-linear regression of the observed plasma concentration point in the terminal phase, and the elimination halflife $\left(t_{1 / 2}\right)$ was calculated as $0.693 / \lambda z$. The apparent total clearance $(\mathrm{Cl} / \mathrm{F})$ and volume of distribution $(\mathrm{Vz} / \mathrm{F})$ were calculated using the formula's dose $/ \mathrm{AUC}_{0-\infty}$ and dose $/\left(\lambda \mathrm{z}^{*} \mathrm{AUC}_{0-\infty}\right)$, respectively.

Each experiment was repeated at least three times. The results are expressed as the mean \pm SD One-way analysis of variance was used to test the statistical significance of differences among groups. Statistical significance of the differences of the means was determined by Student's t-test.

Proton-pump inhibitors (PPIs) have emerged as the drug class of choice for treating patients with acid-related diseases, including gastroesophageal reflux disease (GERD), duodenal ulcer, and gastric ulcer. Patients with Barrett's esophagus and Zollinger-Ellison syndrome benefit from PPIs as well. The gastric acid pump, $\mathrm{H+}, \mathrm{K}+-$ adenosine triphosphatase (ATPase), in the canalicular membrane of the parietal cell is targeted by these drugs, which reduce gastric acid secretion [23]. Acid secretion regulation is a complicated process involving a variety of cell types, hormones, and mediators, yet al. 1 of these processes converge in a final common phase involving $\mathrm{H}+, \mathrm{K}+-$ ATPase. As a result, PPIs effectively inhibit acid secretion in a manner independent of the processes that stimulate the parietal cell [24].

PPIs in the form of tablets are widely prescribed by medical practitioners, but the oral route of administration is reducing the bioavailability due to the first-pass hepatic metabolism. So, in this present study, an attempt was made to study the effect of transdermal patches on the alteration of pharmacokinetic parameters of some selected PPIs such as pantoprazole and esomeprazole.

The transdermal patches were formulated by a solvent evaporation method using different polymers. The drug to polymer concentration was fixed as 1:1 and the polymer to polymer concentration was 1:1,1:2, and 2:1. The transdermal patches were formulated and evaluated for various parameters. The in vitro studies confirmed that the formulations F1 and F7 formulated with HPMC E5: PVP K30 in the ratio of 1:1 released the drugs pantoprazole $98.99 \%$ and Esomeprazole $95.93 \%$ respectively at $24 \mathrm{~h}$. So, these two formulations were selected for the in vivo pharmacokinetic studies on rabbits.

Female New Zealand white rabbits of either and the same age, weighing about 1.5 to $1.75 \mathrm{~kg}$ were used for the study. The rabbits of the first and second groups were administered with the transdermal patches of F1 and F7. The third and fourth groups were administered with the respective marketed formulations along with $100 \mathrm{ml}$ of water. The drug concentrations in plasma after the administration of pantoprazole and esomeprazole in all four groups were followed for $24 \mathrm{~h}$. The PPIs concentrations in plasma were assayed using a validated high-performance liquid chromatography with the RP-HPLC method. The mean plasma concentration versus time profiles for PPIs after a single oral dose of PPIs is shown in fig. 1. The pharmacokinetic parameters were calculated by using PKSolver. The results are shown in table 2.

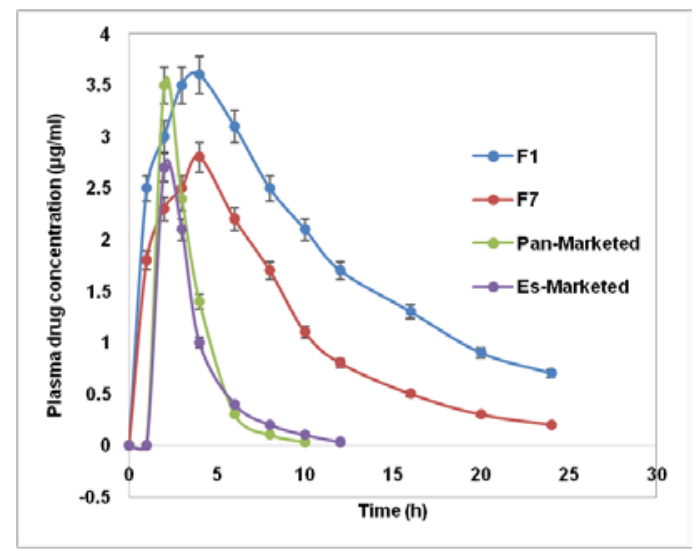

Fig. 1: Mean plasma concentration of PPIs after a single oral administration and transdermal patches ( (mean $\pm S D ; n=3)$

The absorption of pantoprazole and esomeprazole was rapid in marketed formulation than the formulated transdermal patches; the mean $t_{\max }$ of the marketed pantoprazole and esomeprazole was found to be $2 \mathrm{~h}$, while in the tested transdermal patches F1 and F7, the mean $t_{\max }$ was around $4 \mathrm{~h}$. This shows that the formulated transdermal patches were effective in delaying the peak plasma concentration of pantoprazole and esomeprazole. The time to achieve maximum plasma concentrations of PPIs following administration of the marketed tablets used in this study showed relatively $2 \mathrm{~h}$ post-dose between the subjects studied. This is probably a result of the use of an enteric-coated formulation. A similar study was conducted by Pue et al., which showed the relative variability of 2-4 $\mathrm{h}$ in the subjects treated with pantoprazole [25]. 
Table 2: Non-compartmental extravascular pharmacokinetic parameters after single-dose administration of pantoprazole and esomeprazole on rabbits

\begin{tabular}{|c|c|c|c|c|}
\hline \multirow[t]{2}{*}{ Parameters } & \multicolumn{4}{|l|}{ Values } \\
\hline & F1 & F7 & Pantoprazole marketed formulation & Esomeprazole marketed formulation \\
\hline$\lambda_{\mathrm{z}}\left(\mathrm{h}^{-1}\right)$ & 0.0693203 & 0.115611 & 0.615131 & 0.4401033 \\
\hline $\mathrm{t}_{1 / 2}(\mathrm{~h})$ & 9.997071565 & 5.99426 & 1.126589 & 1.57463032 \\
\hline $\mathrm{T}_{\max }(\mathrm{h})$ & 4 & 4 & 2 & 2 \\
\hline $\mathrm{C}_{\max }(\mu \mathrm{g} / \mathrm{ml})$ & 3.6 & 2.8 & 3.5 & 2.7 \\
\hline $\mathrm{AUC}_{0-\mathrm{t}}(\mu \mathrm{g} * \mathrm{~h} / \mathrm{ml})$ & 45.1 & 26.8 & 8.86 & 7.79 \\
\hline $\mathrm{AUC}_{\mathrm{t}-\infty}\left(\mu \mathrm{g}^{*} \mathrm{~h} / \mathrm{ml}\right)$ & 10.09805209 & 1.729945 & 0.04877 & 0.068165815 \\
\hline $\mathrm{AUC}_{0-\infty}(\mu \mathrm{g} * \mathrm{~h} / \mathrm{ml})$ & 55.19805209 & 28.52995 & 8.90877 & 7.858165815 \\
\hline $\operatorname{AUMC}_{0-\mathrm{t}}\left(\mu \mathrm{g}^{*} \mathrm{~h}^{2} / \mathrm{ml}\right)$ & 409.8 & 200.7 & 28.4 & 28.78 \\
\hline $\operatorname{AUMCt}_{-\infty}\left(\mu \mathrm{g}^{*} \mathrm{~h}^{2} / \mathrm{ml}\right)$ & 1.533057851 & 0.438017 & 0.04898 & 0.050625 \\
\hline $\operatorname{AUMC}_{0-\infty}\left(\mu \mathrm{g}^{*} \mathrm{~h}^{2} / \mathrm{ml}\right)$ & 411.3330579 & 201.138 & 28.44898 & 28.830625 \\
\hline $\operatorname{MRT}(\mathrm{h})$ & 7.451948797 & 7.050067 & 3.193368 & 3.668874605 \\
\hline $\mathrm{Vz} / \mathrm{F}(\mathrm{L})$ & 10.2215618 & 11.93707 & 2.89806 & 6.066378709 \\
\hline $\mathrm{Cl} / \mathrm{F}(\mathrm{L} / \mathrm{h})$ & 0.708561731 & 1.380052 & 1.782688 & 2.669833289 \\
\hline
\end{tabular}

(All values are calculated from the mean of Plasma drug concentration; $n=3$ )

The peak plasma concentrations $\left(\mathrm{C}_{\max }\right)$ were 3.6 and $3.5 \mu \mathrm{g} / \mathrm{ml}$, respectively for the formulated transdermal patches and the marketed formulation of pantoprazole and 2.8 and $2.7 \mu \mathrm{g} / \mathrm{ml}$, respectively for the formulated transdermal patches and the marketed formulation of esomeprazole. It indicates there is no significant change in the peak plasma concentration when it was given as a controlled release formulation of transdermal patch or a conventional marketed release formulation, which assures both the formulations F1 and F7 were in the same therapeutic window of the marketed formulations. The $\mathrm{K}_{\mathrm{el}}$ values were found to be 0.0693 , $0.1156,0.6151$, and $0.4401 \mathrm{~h}^{-1}$, respectively, for the formulations $\mathrm{F} 1$ and F7 and the marketed formulations of pantoprazole and esomeprazole, calculated from the slope of the plasma concentration-time data. A decrease in the elimination rate constant of formulations F1 and F7 indicated the slow/sustained release of the drug pantoprazole and esomeprazole in rabbits

$\mathrm{AUC}_{0-\infty}$ in plasma were 55.198, 28.530, 8.909, and $7.858 \mu \mathrm{g} . \mathrm{h} / \mathrm{ml}$, respectively, for the formulations $\mathrm{F} 1, \mathrm{~F} 7$, and marketed formulations of PPIs pantoprazole and esomeprazole, respectively, which indicated the increased bioavailability of the transdermal formulation. The AUC of the formulation F1 and F7 was increased almost 4-6 fold when compared with their respective marketed formulations, which shows the sustained release of the drug pantoprazole and esomeprazole for an extended period. The elimination rate of both the PPIs was relatively fast with a $t_{1 / 2}$ of 9.99 and $5.99 \mathrm{~h}$ for the test formulations and 1.127 and $1.574 \mathrm{~h}$ for the marketed formulations. The $t_{1 / 2}$ values were found to vary widely; similar results were reported by Hassan et al. and Kamdi et al. [26, 27]. The other parameters, like AUMC were also found to be higher in the F1 and F7 formulations. The controlled release characteristics of the formulated transdermal patches of PPIs were reflected in the MRT. The MRT was noticeably increased (2 fold) following oral administration of the PPIs formulations $(7.45,7.05 \mathrm{~h})$ for the formulations F1, F7, and $(3.19,3.66 \mathrm{~h})$ for the marketed pantoprazole and esomeprazole formulations.

In this present study, each animal was administered with $40 \mathrm{mg}$ of either pantoprazole or esomeprazole transdermal patches or the marketed formulations of the same for the evaluation of alteration of pharmacokinetic parameters of these two PPIs. A significant difference was observed in all the pharmacokinetic parameters between both the formulations when compared with the marketed formulation. Thus, the results of the present study indicated the applicability of transdermal patches in the alteration of pharmacokinetic parameters of the PPIs pantoprazole and esomeprazole. The study was concluded that enhancement in the bioavailability of studied PPIs would suggest that the transdermal formulation could be used to improve the bioavailability of both the PPIs positively.

\section{FUNDING}

\section{AUTHORS CONTRIBUTIONS}

All authors have contributed equally.

\section{CONFLICTS OF INTERESTS}

All authors have none to declare

\section{REFERENCES}

1. Asbill CS, Michniak BB. Percutaneous penetration enhancers: local versus transdermal activity. Pharm Sci Technol Today 2000;3:36-41.

2. Balaji P, Thirumal M, Gowri R, Divya V, Ramaswamy V. Design and evaluation of matrix type of transdermal patches of methotrexate. Int J Pharm Chem Biol Sci 2012;2:464-71.

3. Das PS, Saha P. Design and characterization of transdermal patches of Phenformin hydrochloride. Int J Curr Pharm Res 2017;9:90-3.

4. Shivalingam M, Balasubramanian A, Ramalingam K. Noninvasive medicated dermal patch-a review. Int J Pharm Res 2020;12:3018-27.

5. Shivalingam MR, Balasubramanian A, Ramalingam K. Design and evaluation of medicated dermal patches of proton pump inhibitor-esomeprazole. Int J Pharm Res 2020;12:3038-43.

6. Funke AP, Schiller R, Motzkus HW, Günther C, Müller RH, Lipp R. Transdermal delivery of highly lipophilic drugs: in vitro fluxes of antiestrogens, permeation enhancers, and solvents from liquid formulations. Pharm Res 2002;19:661-8.

7. Guy RH. Current status and future prospects of transdermal drug delivery. Pharm Res 1996;13:1765-9.

8. Barry BW. Novel mechanisms and devices to enable successful transdermal drug delivery. Eur J Pharm Sci 2001;14:101-14.

9. Madan JR, Dua NSA, K. Formulation and evaluation of transdermal patches of donepezil. Vol. 9. Recent Patents on Drug Delivery and Formulation; 2015. p. 95-103.

10. Selvaraj GJ, Balasubramanian A, Ramalingam K. Development of the mucoadhesive tablet of pentoxifylline using a natural polymer from Manilkara zapota linn. Int J Appl Pharm 2019;11:88-91.

11. Selvaraj GJ, Balasubramanian A, Ramalingam K. Application of novel natural mucoadhesive polymer in the development of pentoxifylline mucoadhesive tablets. Int J Appl Pharm 2019;11:37-41.

12. Huber R, Hartmann M, Bliesath H, Lühmann R, Steinijans VW, Zech K. Pharmacokinetics of pantoprazole in man. Int J Clin Pharmacol Ther 1996;34:185-94.

13. Johnson DA. Review of esomeprazole in the treatment of acid disorders. Expert Opin Pharmacother 2003;4:253-64.

14. Davies JE. The pharmacological basis of therapeutics. Occup Environ Med 2007;64:e2-e2.

15. Singh A, Bali A. Formulation and characterization of transdermal patches for controlled delivery of duloxetine hydrochloride. J Anal Sci Technol 2016;7:1-13. 
16. Shivalingam MR, Arul B, Kothai R. Formulation and evaluation of transdermal patches of pantoprazole sodium. Int J Appl Pharm 2021;13:1.

17. Prabhakara P, Koland M, Vijaynarayana K, Harish NM, Shankar G, Ahmed MG, et al. Preparation and evaluation of transdermal patches of papaverine hydrochloride. Int J Res Pharm Sci 2010;1:259-66.

18. Shivaraj A, Selvam RP, Mani TT, Sivakumar T. Design and evaluation of transdermal drug delivery of ketotifen fumarate. Int J Pharm Biomed Res 2010;1:42-7.

19. Selvaraj GJ, Balasubramanian A, Ramalingam K. Alteration of pharmacokinetic parameters of pentoxifylline using natural mucoadhesive polymers. Int J Appl Pharm 2020;12:153-7.

20. Harahap Y, Baskara AE, Harmita. Method validation of esomeprazole analysis in human plasma using highperformance liquid chromatography-photodiode array. J Young Pharm 2017;9:s24-8.

21. Noubarani M, Keyhanfar F, Motevalian M, Mahmoudian M. Improved HPLC method for determination of four PPIs, omeprazole, pantoprazole, lansoprazole and rabeprazole in human plasma. J Pharm Pharm Sci 2010;13:1-10.
22. Patel BH, Suhagia BN, Patel MM, Patel JR. Determination of pantoprazole, rabeprazole, esomeprazole, domperidone and itopride in pharmaceutical products by reversed-phase liquid chromatography using single mobile phase. Chromatographia 2007;65:743-8.

23. Sachs G. Proton pump inhibitors and acid-related diseases. Pharmacotherapy 1997; 17:22-37.

24. Sachs G, Shin JM, Briving C, Wallmark B, Hersey S. The pharmacology of the gastric acid pump: the $\mathrm{H}+, \mathrm{K}+\mathrm{ATPase}$ Annu Rev Pharmacol Toxicol 1995;35:277-305.

25. Pue MA, Laroche J, Meineke I, de Mey C. Pharmacokinetics of pantoprazole following single intravenous and oral administration to healthy male subjects. Eur J Clin Pharmacol 1993;44:575-8.

26. Kamdi SP, Palkar PJ. Bioequivalence study of pantoprazole sodiumHPBCD and conventional pantoprazole sodium enteric-coated tablet formulations. ISRN Pharmacol 2013;2013:347457.

27. Hassan Alin M, Andersson T, Bredberg E, Röhss K. Pharmacokinetics of esomeprazole after oral and intravenous administration of single and repeated doses to healthy subjects. Eur J Clin Pharmacol 2000;56:665-70. 